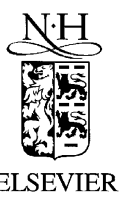

\title{
Market integration and convergence to the Law of One Price: evidence from the European car market
}

\author{
Pinelopi K. Goldberg ${ }^{\mathrm{a}, \mathrm{b}, *}$, Frank Verboven ${ }^{\mathrm{c}, \mathrm{d}}$

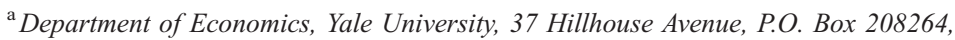 \\ New Haven, CT 06520-8264, USA \\ ${ }^{\mathrm{b}}$ NBER, USA \\ ${ }^{\mathrm{c}}$ Faculty of Economics and Applied Economics, Katholieke Universiteit Leuven, \\ Naamstestraat 69, B-3000 Leuven, Belgium \\ ${ }^{\mathrm{d}} C E P R, U K$
}

Received 10 June 2002; received in revised form 17 December 2003; accepted 23 December 2003

\begin{abstract}
This paper exploits the unique case of European market integration to investigate the relationship between integration and price convergence in international markets. Using a panel data set of car prices, we examine how the process of integration has affected cross-country price dispersion in Europe. We find surprisingly strong evidence of convergence towards both the absolute and the relative versions of the Law of One Price (LOOP). Our analysis illuminates the main sources of segmentation in international markets and suggests the type of institutional changes that can successfully reduce it.
\end{abstract}

(C) 2004 Elsevier B.V. All rights reserved.

Keywords: International price dispersion; Law of one price; Market integration; Price convergence; European automobile market

JEL classification: F0; F15; L62

\section{Introduction}

This paper uses the European integration process as a case study to explore the link between integration and price convergence in international markets. Few topics have attracted as much attention and controversy in International Economics as the topic of

* Corresponding author. Tel.: +1-203-432-3569; fax: +1-203-432-6323.

E-mail addresses: penny.goldberg@yale.edu (P.K. Goldberg), frank.verboven@econ.kuleuven.ac.be (F. Verboven). 
convergence to the Law of One Price (LOOP). While until a few years ago, one was hardpressed to find evidence in favor of the convergence hypothesis, a number of recent papers claim that Purchasing Power Parity does hold in the long run, with a half-life of shocks of 5-5 years (see Obstfeld and Rogoff, 2000 for a detailed discussion). The new evidence comes primarily from "bigger" data sets - use of panel data sets as in Frankel and Rose (1996), Parsley and Wei (1996), Cecchetti et al. (2002), etc., or exploitation of longer timeseries data for individual countries (see Taylor, 2001 for an overview) - and methodological advances (Taylor, 2002). Still, the slow speed of convergence documented in international markets remains a puzzle. In their excellent study of price dispersion across U.S. cities, Parsley and Wei (1996) report half-lives of shocks of four to five quarters for tradeables, a substantially shorter time than the aforementioned 5-6 years estimated in cross-country studies. Engel and Rogers (1996) report that the border between the U.S. and Canada is "2500 miles wide", meaning that crossing the border adds as much to the volatility of prices as adding 2500 miles between cities, while Parsley and Wei (2001) estimate the U.S.-Japan "border" to be 43,000 trillion miles wide. In a recent study, Asplund and Friberg (2001) find that the LOOP does not even hold for identical goods sold at the same location, as long as these goods are dominated in different currencies (the evidence comes from price data of products sold in Scandinavian duty-free stores). While various explanation have been suggested in the literature-with normal exchange rate volatility being the primary contender - there is little agreement as to what factors generate international price dispersion in the first place, and what mechanisms can accelerate convergence to the LOOP.

The goal of this paper is to shed light on the above question by focusing on a period that is characterized by a distinct effort to "integrate" national markets in Europe (1970 2000). The progress towards integration took the form of removal of trade barriers, encouragement - within limits - of arbitrage, harmonization of tax rates and other national regulations, increased transparency, monitoring of cross-country price differences, and, with the creation of the European Monetary Union (EMU), reduction of exchange rate volatility in the later years of our sample. To the extent that price dispersion was driven by any of the above factors, we would expect to see accelerated convergence to the LOOP, especially in the 1990s, when the European Commission's efforts to achieve integration intensified.

Our approach to the above questions deviates from the traditional convergence literature in that it is a distinctly micro approach. We focus on a particular market, the European automobile market, and exploit a large panel data set that we have put together ourselves over several years, containing observations on car prices and characteristics in five countries over the period 1970-2000. We believe that this approach offers three main advantages.

First, the car market has been a notorious example of deviations from the LOOP in international markets. It was no coincidence that Krugman, 1987 chose automobiles as an example of international pricing-to-market in his seminal study in 1987. In a recent study, Crucini et al. (2000) report that the car industry is the only sector for which cross-country price dispersion for the same brand exceeds price dispersion of different brands within the same country (p. 4). This dispersion is the more surprising as automobiles constitute a significant portion of consumer expenditures, so that consumers typically carefully 
research the purchase, and utilize publicly available information on prices and characteristics. In Europe in particular, the persistent and exceedingly large cross-country price differences for virtually identical products have been the focus of intense public debate. The European Commission has considered the European auto market a test case for integration and ordered several investigations into the sources of these price differences. Furthermore, it has taken concrete steps to integrate the national markets and reduce price dispersion. Hence, the car market is a natural starting point in an investigation of the relationship between market integration and convergence.

Second, while recent studies seem to "converge" in their findings on PPP, the evidence pertains primarily to the relative versions of LOOP or PPP. As pointed out in Goldberg and Knetter (1997) and Knetter and Slaughter (2001), this preoccupation with the relative versions reflects data realities rather than research interests - typically, the data employed in price comparisons are fairly aggregate price data or price indices (Parsley and Wei's use of disaggregate product level data from ACCRA, and Haskel and Wolf's (2001) product level data from IKEA stores are notable exceptions). In general, disaggregate data are easier to obtain for national markets, which is one of the reasons that studies of the absolute version of the LOOP tend to focus on a single country. Disaggregate price data for multiple countries need to be assembled individually, on a product-by-product basis from national industry journals written in many different languages. ${ }^{1}$ Even when disaggregate data are available, it is rarely the case that the identical goods assumption needed for the absolute version of the LOOP holds. Yet, there is little doubt that absolute price differences can be indicative of market segmentation; few of us, for example, would characterize Europe as an "integrated" market if there were a constant $\$ 3000$ difference in the price of a Toyota Corrolla across Belgium and Germany. One of the strengths of our data set - and this is why we had to collect the data ourselves - is that the detail of the information (prices of individual car models plus characteristics) allows us to compare prices of homogeneous products across countries, and hence test not only the relative, but also the absolute version of the LOOP.

The potentially different implications of the relative versus absolute version of the LOOP for the question of market integration are illustrated in one of our earlier papers (Goldberg and Verboven, 2001b). This paper documents large deviations from the absolute version of LOOP that are subsequently explained within the framework of a structural product differentiation model. The paper concludes that based on the evidence on absolute price differences, the European car market cannot be characterized as integrated. In contrast, the relative version of the LOOP does not fare that badly during the period of investigation (1980-1993); pass-through regressions (that include country fixed effects) yield an average exchange rate pass-through coefficient of 0.54 , a surprisingly high estimate given the use of retail c.i.f. (and not f.o.b.) price data. The auto market would thus

\footnotetext{
${ }^{1}$ Haskel and Wolf (2001) are the only other study to our knowledge that undertook such a task; the authors assembled data for several products sold by IKEA in various countries. The focus of their study is however more on price comparisons across countries in any given year, rather than on the dynamic issue of price convergence addressed in our paper. This is partly dictated by the nature of our data sets; Holger and Wolf have data for 29 countries but only 4 years, while we have data for 5 countries but 30 years.
} 
appear to be more "integrated" based on evidence on relative rather than absolute price dispersion.

Given the recent efforts of the European Commission to promote integration in the European auto market, a natural question to ask is what has happened to the cross-country price dispersion. To address this question, we extend the sample used in our previous work in both directions, to include earlier years from the 1970s that precede integration efforts, as well as more recent years from the late 1990s when the European Commission's integration activity is at its peak. Although we do not anticipate the structural factors causing persistent cross-price differentials that we identified in our previous work (price elasticities of demand, local costs, trade policies) to become obsolete overnight, we would expect progress towards integration to translate to lower price differentials across markets for reasons we outline later in our analysis.

A third advantage of the micro analysis is that the focus on a particular market allows for a more in-depth analysis of the institutional details. It is the institutional analysis that helps us understand the sources of market segmentation and relate particular measures aimed at integration to actual price convergence.

The remainder of the paper is organized as follows. In Section 2, we provide a brief overview of the data and the sources of segmentation in the European car market, and discuss the steps that have been taken in the last two decades to promote integration. Section 3 considers various specifications of convergence equations and reports our findings. To summarize our results, we find evidence in favor of convergence towards both the relative and the absolute versions of the LOOP. For the relative version of the LOOP in particular, our estimated speed of convergence implies a half-life of a shock between 1.3 and 1.6 years. While this estimate is consistent with the results of our earlier paper that document relatively high exchange rate pass-through in the European car market, it seems surprisingly high when compared to previous studies of international price dispersion. Moreover, we find equally high speeds of convergence when we run separate regressions for each country pair, thus giving up the cross-sectional dimension of our panel data. This contrasts with the widely held view in the literature that it was the transition from timeseries to panel data that allowed researchers to find support for the convergence hypothesis. Our results also seem to contrast with the findings of an earlier paper by Gagnon and Knetter (1995) that focuses on the same market (automobiles), but uses data from a different set of countries and finds strong evidence against the relative version of the LOOP. We should emphasize that we do not view these results as constituting evidence in favor of the universal validity of the relative LOOP; rather, we attribute the surprisingly strong evidence in support of the convergence hypothesis found in our data to the progress towards integration in the European market. ${ }^{2}$

Regarding the absolute version of the LOOP, the results are more mixed. The bad news for integration is that we estimate large, highly significant product/country fixed effects in regressions testing the relative version, which suggest the existence of large, persistent price differentials across countries. The magnitude of these differentials (as

\footnotetext{
2 Our results are in line with the findings of a recent paper by Rogers (2002) that finds a striking decline in traded goods price dispersion in Europe between 1991 and 1994.
} 
high as $17 \%$ between the U.K. and Belgium) is comparable to the one estimated in our previous paper and seems at odds with the notion of integrated markets. The good news for the integration hypothesis however is that these differentials seem to be declining over time: when we break down the sample and estimate the convergence equations with fixed effects for various subperiods, we find that the fixed effects are substantially lower in subperiods that cover the later years of our sample. Moreover, tests of the absolute version of the LOOP based on convergence equations without fixed effects reject the hypothesis of a unit root. A natural way to reconcile the statistical evidence in favor of the absolute LOOP with the existence of large fixed effects in tests of the relative version over our sample period is that: (a) there are country-specific structural factors (e.g., differences in price elasticities of demand, trade policies, local distribution costs, etc.) that cause deviations from the absolute LOOP in each period; (b) prices converge quickly to these structurally determined deviations, as the results on the relative LOOP suggest; (c) at the same time, as a consequence of the recent integration efforts and encouragement of cross-country arbitrage, the structural factors causing cross-price differences are fading in importance, so that the deviations from the absolute LOOP are themselves (slowly) converging to zero. Overall, our results paint the picture of a market in which substantial cross-price differences still exist, but where progress towards integration is evident.

\section{Preliminary data analysis}

The data set we have constructed to examine price convergence is a large three dimensional panel, containing information on approximately 150 vehicle makes per year in five distinct European markets over the period 1970-2000. For each make, we have information on sales, list price, and physical characteristics such as engine attributes, dimensions, and performance variables; these characteristics sometimes vary across markets. The five markets included in our analysis are Belgium, France, Germany, Italy, and the United Kingdom. We focus our attention on these five countries, both because of data availability constraints, and, more importantly, because they represent the largest markets in Europe: collectively they account for over $85 \%$ of total car sales in Europe every year. In addition, these countries represent a large spectrum for several reasons: the size of the market varies from ca. 400,000 units/year in Belgium to almost 3 million cars in Germany; the degree of import penetration ranges from ca. 30\% in France and Germany to almost $100 \%$ in Belgium; the Japanese penetration varies from ca. $1 \%$ in Italy to $20 \%$ in Belgium; tax rates vary from $14 \%$ in Germany to $33 \%$ in France in the early years, and $25 \%$ later; and the $\mathrm{C} 1$-concentration index ranges from $53 \%$ in Italy to $16 \%$ in Belgium; throughout our sample period Belgium tends to be the cheapest destination, while the U.K. is associated with the highest prices.

Because our information is at the vehicle make level, our cross-country price comparisons refer to relatively homogeneous products (for example, we are comparing the price of a Honda Civic in Belgium to the price of a Honda Civic in Germany). In this sense, our products are more likely to satisfy the homogeneity assumption than many of the goods that are named as classical textbook examples of homogeneous commodities (e.g., agricultural 
products, pencils, lightbulbs, etc.). Such products are often differentiated by location of production or brand name. In contrast, our focus on specific vehicle makes conditions on both producer and brand. Nevertheless, to be absolutely sure that we are comparing physically homogeneous products, we use hedonic price regressions (which we describe in more detail below) to control for possible variation in characteristics or options of models across countries, and use the residuals of these regressions as the relevant prices in our price convergence regressions.

Even after controlling for observable differences of narrowly defined products across countries (such as engine or performance differences), one could argue that products sold in different markets are not entirely homogeneous. The homogeneity assumption could, for example, be violated in our case because of unobserved product characteristics that may differ across markets, the existence of different discount practices in different countries, or transportation costs (though the magnitude of the price differentials in individual years makes it unlikely that any of these factors could by itself explain the documented price dispersion). Before we proceed, it is therefore useful to make clear what the role of the homogeneity assumption in our analysis is.

The homogeneity assumption is only needed in the context of tests of the absolute version of the LOOP. Tests of relative price convergence will be unaffected by violations of the homogeneity assumption, if the relative importance of factors explaining price dispersion do not change much over the sample period. ${ }^{3}$ This is precisely the reason that most of the literature on this subject has focused on the relative version of the LOOP. Regarding the absolute version of LOOP, violations of the "homogeneous good" assumption would make us more likely to reject the hypothesis of convergence to the absolute version of the LOOP. In this sense, the fact that we do find convergence towards the absolute version of the LOOP-despite potential violations of the homogeneity assumption - makes the case for the validity of the LOOP even stronger.

A rough first idea about the magnitude of the price differences can be obtained from Fig. 1 that plots the maximum percentage bilateral cross-country price differences for several models, against the average price of the model across the five markets. The figure

\footnotetext{
3 With respect to discounts in particular, our sources indicate that they did not change much over our sample period. The BEUC (1992) provides a comparison between the 1989 and 1992 maximum discounts, and reports the following changes between the two years: Belgium: from $11 \%$ to $10 \%$, France: $8 \%$ in both years, Germany: from $10 \%$ to $8 \%$, U.K. from $15 \%$ to $11 \%$, Italy: not available. Degryse and Verboven (2000) find similar small variations in the gross dealer margins (at the brand level), based on questionnaires mandated by the European Commission. Gross dealer margins are a measure of the maximum discounts and financial benefits a dealer can offer to consumers. They changed as follows between 1993 and 1999: in Belgium (country average) from 17\% to $15 \%$, in France from $17 \%$ to $15 \%$, in Germany from $19 \%$ to $17 \%$, in Italy from $18 \%$ to $16 \%$ and in the U.K. from $17 \%$ to $13 \%$. These differences in discounts across countries are too small in comparison to the price differentials to explain the price dispersion in any given year, and the changes over time (and especially the cross-country differences in these changes) are too small to explain price convergence. Although there is no guarantee that the stability of discounts applies to the remaining years of our sample, the absence of any discussion on the role of discounts from the public debate is perhaps the best indication that cross-country differences in discount practices are of secondary importance when it comes to explaining international price dispersion in automobiles.
} 


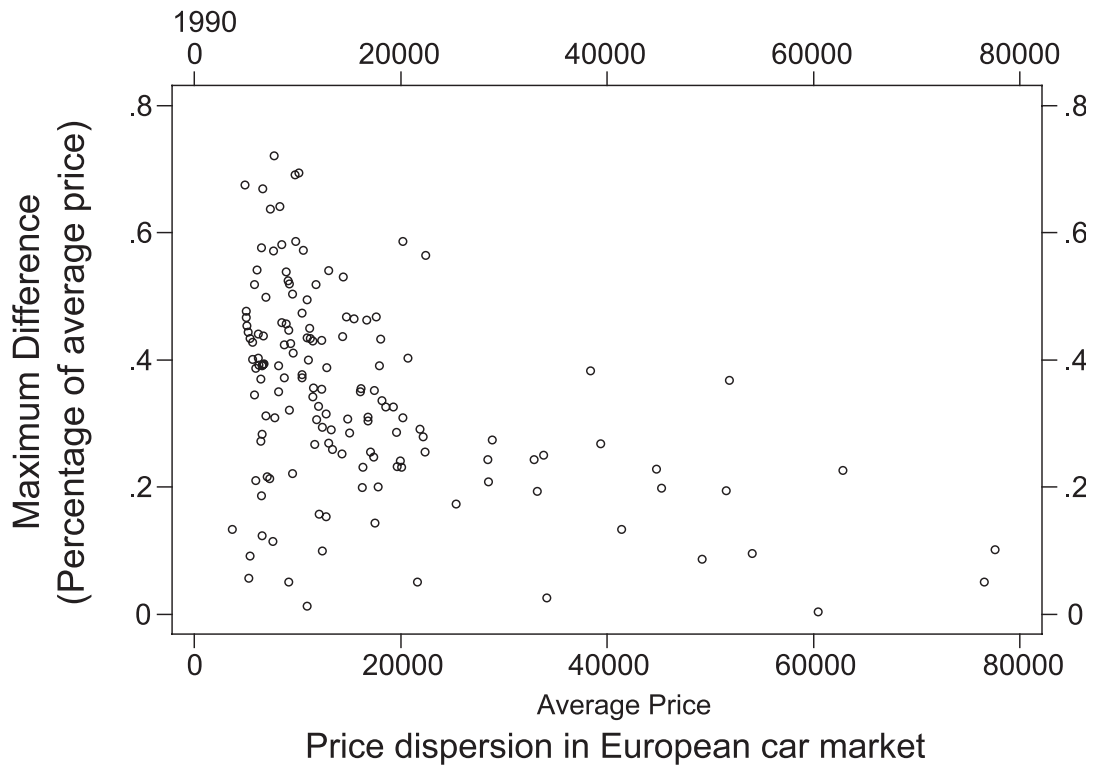

Fig. 1. Price dispersion in the European car market.

refers to year 1990, but plots for other years are similar. The average cross-country price differential is 35\%; for some models, it is as high as $75 \%$ (\% for example, the Toyota Corolla and Jaguar XJ6). A similar message is conveyed by Fig. 2 that is based on

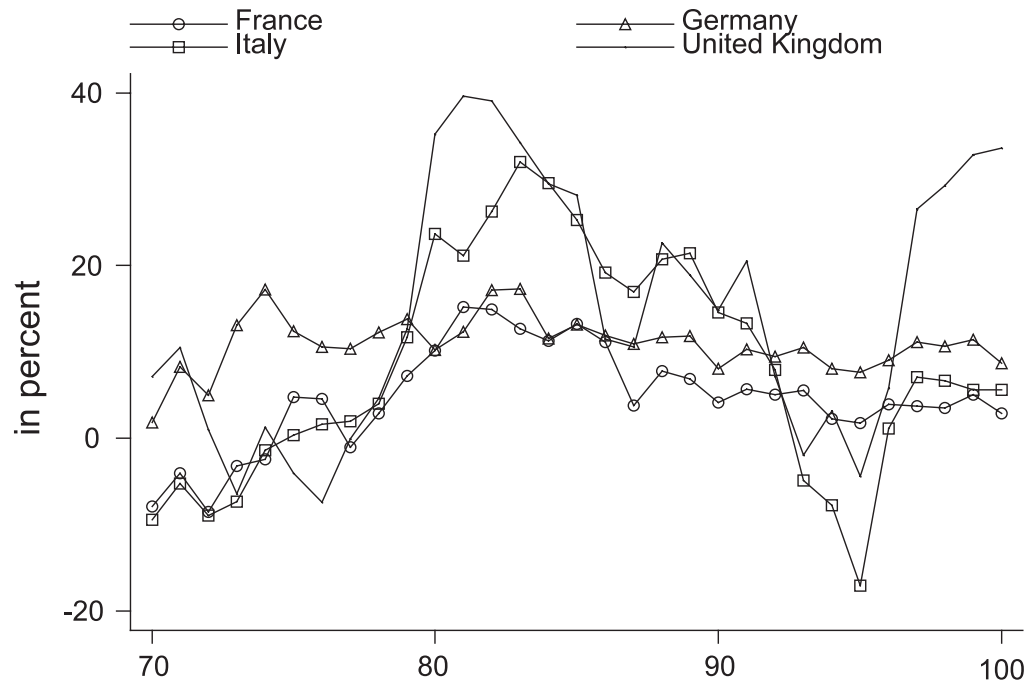

Based on destination country/time effects in hedonic regression

Fig. 2. Evolution of car price differentials, relative to Belgium. 
aggregate price indices for the five countries. To construct these aggregate price indices, we ran the following hedonic price regression:

$$
\ln \left(r p_{i, k, t}^{\text {Euro }}\right)=w_{i, k, t} \gamma+\theta_{\mathrm{c}}+\theta_{\mathrm{f}}+\theta_{s, t}+\theta_{k, t}+\varepsilon_{i, k, t}
$$

The subscripts $i, k$, and $t$ refer to product $i$, country $k$, and year $t$, respectively. The variable $r p_{i, k, t}$ refers to the raw, pre-tax price of car model $i$ expressed in a common currency (Euro). The vector $w_{i, k, t}$ consists of physical car characteristics that may vary across markets, while $\theta_{\mathrm{c}}$ and $\theta_{\mathrm{f}}$ are market segment and firm dummies, respectively. In addition, we include a set of source country/time dummies $\left(\theta_{s, t}\right)$ to control for differences that may be due to a common cost shock facing firms located in a particular country of origin (e.g., an increase in wages facing all Japanese firms). ${ }^{4}$ Given this specification, the destination/time effects $\theta_{k, t}$ capture the residual cross-country price differences that cannot be explained by differences in quality or taxation across markets. All differences are measured in percentage terms relative to Belgium. ${ }^{5}$

Fig. 2 plots the estimated price indices $\theta_{k, t}$ for the period 1970-2000. The figure documents the same patterns reported in Goldberg and Verboven (2001a) for a sub-period of this sample: (1) large and persistent cross-country price differentials and (2) substantial year-to-year volatility. Belgium appears to be the cheapest country throughout the sample period, while the U.K. is - in most years - the most expensive. These patterns were robust to alternative specifications of the hedonic equation. ${ }^{6}$ Moreover, they were robust to the use of more disaggregate price indices. For example, using a similar hedonic price framework as the one described above, we estimated and plotted price indices for each market segment separately (small, large, luxury, sports cars, etc.). The graphs exhibited approximately the same magnitude and same volatility of price dispersion, indicating that the patterns evident in Fig. 2 are not driven by aggregation.

The large price differences documented in the previous graphs leave little doubt that European car market is segmented along national lines. This sentiment is confirmed by a careful institutional analysis of this market that reveals three main sources of segmentation: (1) the differing national systems of type approval that dictated until recently costly modifications of imported vehicles; (2) a unique system of selective and exclusive distribution that is sanctioned by Regulation 123/85 and that has in the past allowed auto manufacturers to prevent their dealers from selling to unauthorized resellers, in particular if the purchase was intended for export; (3) national import quota constraints combined with the system of national registration, which has had the effect of limiting cross-country trade

\footnotetext{
4 The source country refers to the production location of the individual car models. If a car has production locations in multiple countries, we take the production location that is closest to the destination country; hence, several "Japanese" brands have the U.K. as a source country in the later years of our sample.

5 All coefficients in the hedonic price regression had the expected signs and were precisely estimated. The $R^{2}$ of the regression was 0.97 . The full set of results is available from the authors upon request.

6 The graph does not display confidence bands, since too many lines would render the figure illegible. We should note however that all destination/time effects are highly significant. At the bottom of Fig. 2, we present confidence intervals for selected years that demonstrate that the cross-country differences discussed above are statistically significant.
} 
of foreign, mainly Japanese models. ${ }^{7}$ Given these restrictions on cross-country arbitrage, it is not surprising that markets are segmented. What is perhaps less well understood is why it is in the interest of auto suppliers to erect the barriers mentioned above in order to keep maintain segmentation.

In our earlier paper (Goldberg and Verboven, 2001b), we address this question by identifying the reasons that auto manufacturers will want to take advantage of this segmentation: a strong preference for domestic brands that translates to market power of firms selling in Italy; cost differences that account for the higher prices in the U.K.; differing impact of restrictive trade policies (VERs); finally, markup adjustment and local distribution costs that prevent local currency prices from fully adjusting to exchange rate changes.

Against this background, it is natural to ask which specific sources of cross-country price dispersion the European Commission has targeted in order to foster integration. The main goal of the European Commission's activity has been to promote price transparency and cross-country arbitrage, by carefully monitoring cross-country price differences, making the results of price dispersion studies publicly available, and eliminating many of the sources of segmentation. Several measures were taken to this end: the gradual harmonization of the so-called "essential requirements" for new car models throughout the European Union; the harmonization and eventual (in 1999) removal of the import quota constraints on Japanese cars; finally, attempts to prevent dealers and manufacturers from abusing the selectivity and exclusivity of the distribution system. Although the distribution system was not changed in its essence, and it remains restrictive, there has been a stricter enforcement of the " $12 \%$ rule" the condition that manufacturers could not restrict consumers or intermediaries acting on their behalf, from purchasing a car from any dealer. In addition, European policy has also tried to target the sources of cross-country cost differences directly. An example of such an effort constitutes the harmonization of tax rates; as Table 1 indicates, tax rate differences are now smaller compared to their levels in the past. The transition to a system of fixed exchange rates should also contribute to a reduction of the year-to-year variation in price differentials.

As a result of this activity, one would expect price differentials to decline over time. While the European Commission's efforts cannot completely eliminate all sources of price dispersion (for example, to the extent that price differences reflected local cost differences across countries, or local tastes for some unobserved product characteristics, some crosscountry price dispersion would remain), the encouragement of cross-country arbitrage alone should put pressure on auto manufacturers and dealers to "harmonize" auto prices across European markets. Yet, one would be hard-pressed to claim price convergence, when looking at Fig. 2. What is perhaps most surprising is that, while prices seem to be coming together around 1990-1992, they start diverging again after 1992, a development that certainly runs against the idea of the integrated "Europe 1992". A closer examination

\footnotetext{
7 We refer the reader to the NBER working paper version of this work that provides more detail on the institutions.

8 This "rule" authorizes the European Commission to withdraw the benefits of the selective distribution system if price differences across countries exceed $12 \%$.
} 
Table 1

Summary statistics for the European car market ${ }^{\mathrm{a}}$

\begin{tabular}{|c|c|c|c|c|c|c|}
\hline & $\mathrm{BE}$ & FR & GE & IT & UK & All \\
\hline \multicolumn{7}{|l|}{ Value-added tax (in \%) } \\
\hline Up to 1983 & 25 & 33 & 13 & 18 & 23.3 & \\
\hline 1990 & 25 & 25 & 14 & 19 & 23.3 & \\
\hline 1995 & 20 & 21 & 15 & 19 & 17.5 & \\
\hline 2000 & 21 & 21 & 16 & 20 & 17.5 & \\
\hline Total sales (in 1000 units) & $\begin{array}{l}347.5 \\
(69.6)\end{array}$ & $\begin{array}{l}1670.8 \\
(350.8)\end{array}$ & $\begin{array}{l}2329.9 \\
(377.1)\end{array}$ & $\begin{array}{l}1562.0 \\
(403.5)\end{array}$ & $\begin{array}{l}483.3 \\
(338.5)\end{array}$ & $\begin{array}{l}7393.6 \\
(1304.2)\end{array}$ \\
\hline Parallel imports (in 1000 units) ${ }^{\mathrm{b}}$ & $\mathrm{N} / \mathrm{A}$ & $5-40$ & $30-60$ & $10-75$ & $1-50$ & \\
\hline \multicolumn{7}{|l|}{ Japanese market share (in \%) } \\
\hline In 1970 & 4.6 & 0.1 & 0.1 & 0.0 & 0.1 & 0.3 \\
\hline In 1980 & 24.6 & 2.9 & 10.4 & 0.1 & 11.9 & 7.6 \\
\hline In 1990 & 19.4 & 3.0 & 12.8 & 0.7 & 11.5 & 7.7 \\
\hline In 2000 & 19.9 & 5.0 & 15.0 & 6.1 & 11.9 & 11.6 \\
\hline Japanese quota (in \%) ${ }^{\mathrm{c}}$ & - & 3.0 & 15.0 & 1.0 & 11.0 & \\
\hline Domestic market share (in \%) & $\begin{array}{l}2.3 \\
(1.6)\end{array}$ & $\begin{array}{l}68.1 \\
(10.5)\end{array}$ & $\begin{array}{l}69.7 \\
(4.6)\end{array}$ & $\begin{array}{l}54.7 \\
(16.6)\end{array}$ & $\begin{array}{l}58.4 \\
(9.3)\end{array}$ & \\
\hline Corresponding European average (in \%) & $\begin{array}{l}2.0 \\
(0.9)\end{array}$ & $\begin{array}{l}25.5 \\
(4.7)\end{array}$ & $\begin{array}{l}33.6 \\
(4.2)\end{array}$ & $\begin{array}{l}14.8 \\
(4.9)\end{array}$ & $\begin{array}{l}13.2 \\
(2.2)\end{array}$ & \\
\hline C1-ratio (in \%) & $\begin{array}{l}16.5 \\
(1.9) \\
(\mathrm{VW})\end{array}$ & $\begin{array}{l}33.9 \\
(2.9) \\
\text { (PSA) }\end{array}$ & $\begin{array}{l}29.2 \\
(2.5) \\
(\mathrm{VW})\end{array}$ & $\begin{array}{l}51.6 \\
(12.9) \\
\text { (Fiat) }\end{array}$ & $\begin{array}{l}28.8 \\
(4.4) \\
\text { (Ford) }\end{array}$ & $\begin{array}{l}15.7 \\
(1.6) \\
\text { (Fiat) }\end{array}$ \\
\hline
\end{tabular}

${ }^{a}$ Averages, over 1980-1995. Standard deviations in parentheses.

${ }^{\mathrm{b}}$ Ranges between 1981 and 1992, based on estimates from $\operatorname{BEUC}(1981,1986,1989,1992)$.

${ }^{\mathrm{c}}$ Figures until 1990 (VERs for Germany and UK). Between 1991 and 1998: a Europe-wide quota of 8\%. Since 1999: no quota.

of the graph reveals that it is the prices in the U.K. and Italy that diverge the most. These two countries however experienced large currency fluctuations in the 1990s that may have affected price convergence. More generally, the price volatility exhibited in Fig. 2 immediately brings exchange rates to mind, as there is no other source of price dispersion as volatile as nominal exchange rates. Fig. 3 plots the exchange rates of the countries in our sample vis a vis Belgium; the correlation between the evolution of price differences in Fig. 2 and the exchange rate fluctuations in Fig. 3 is apparent. ${ }^{9}$

Since the existence of price convergence over our sample period does not seem to be an issue that can be settled through graphs or simple statistics, we now turn to a more systematic investigation of price convergence.

\section{Results on price convergence}

This section investigates different versions of price convergence. We start by documenting the persistence of long-term price differentials and providing an estimate of the

\footnotetext{
${ }^{9}$ Correlations of year-to-year changes in bilateral price differences and year-to-year changes in bilateral exchange rates exceed 0.8 , indicating that, in the short run, price differences are highly correlated with exchange rate changes.
} 




Fig. 3. Evolution of exchange rates, relative to Belgium.

speed of convergence to the relative version of the LOOP, i.e. how fast deviations from the long-term price differentials are eliminated. Next, we investigate the effects of the integration process; in particular, we examine whether long term price differentials have decreased over time and whether the speed of convergence has increased.

Before we proceed, let us introduce some notation. Let $q_{i, k, t}$ denote the log-price of product $i$ in country $k$ at time $t$ and $p_{i, k, t}$ denote the log-price of this same product relative to a benchmark country $B$ (that is, $p_{i, k, t}=q_{i, k, t}-q_{i, B, t}$, with $p_{i, B, t}=1$, for all $i$ and $t$ ). In constructing the dependent variable of our convergence equations, we face two choices: we can base the specification of the dependent variable on $q$, in which case the term "cross-country price differentials" will have to be understood as the differences of an individual country's car prices from a theoretical cross-country average; or, we can use $p$ to construct the dependent variables in our regressions, in which case the term "cross-country price differentials" refers to the differences of a country's prices from the prices of the benchmark country. In either case, the dependent variable will involve the first time-difference $\Delta$ of the price differentials as defined above $\left(\Delta q_{i, k, t}=q_{i, k, t}-q_{i, k, t-1}\right.$ or $\left.\Delta p_{i, k, t}=p_{i, k, t}-p_{i, k, t-1}\right)$. The idea, as in all papers that test for unit roots, is to relate this first difference to the log-price of the previous period; if the coefficient on the previous period's price is negative, price differentials across countries become smaller over time, and the hypothesis of a unit root is rejected.

We chose the second approach with Belgium as the numeraire country. Belgium provides a natural benchmark as it is both the country with typically the lowest car prices in Europe, and the market with the fewest trade restrictions and lowest concentration. In the context of arbitrage, we find it more appealing to focus on bilateral price differences 
relative to the cheapest country, rather than on deviations from a theoretical cross-country average. A possible criticism of this approach is that the convergence results are not invariant to the choice of the numeraire country (see Papell, 1997; Wei and Parsley, 1995; Cecchetti et al., 2002). To address this criticism we also estimated convergence equations using different countries as the benchmark (e.g., Germany), and also experimented with using $q$ as the basis for constructing the dependent variable. ${ }^{10}$ In both cases, our results were very similar to the ones reported below, so that we are confident that our conclusions are not due to the particular choice of the base country.

Because some of the vehicle makes are not available for all 31 years in our sample, our panel is unbalanced. For example, several Japanese and Korean models were only introduced in the late seventies. Other models stopped being produced (this usually happened if the firm owned another successful model in the same segment). To deal with this issue we used the following procedure: First, we run hedonic price regressions to control for quality and firm reputation differences across markets. These regressions also include interactions of market segment/country of origin/destination market/time dummies on the right hand side. The coefficients of these dummies represent representative qualityadjusted averages of individual vehicle make prices during each year, by market segment, country of origin, and destination country. We use these quality-adjusted prices to form the dependent variable used in the estimation.

\subsection{The basic convergence equation}

We start by estimating the following basic version of the convergence equation:

$$
\Delta p_{i, k, t}=\alpha_{i, k}+\beta p_{i, k, t-1}+\sum_{l=1}^{L} \gamma_{l} \Delta p_{i, k, t-l}+\varepsilon_{i, k, t}
$$

Our estimation procedure is based on the work of Levin and Lin (1992) on unit root tests with panel data. As noted above, the dependent variable is the first difference in the log-price of product $i$ in country $k$ relative to Belgium $\left(\Delta p_{i, k, t}=p_{i, k, t}-p_{i, k, t-1}\right.$, with $\left.p_{i, k, t}=q_{i, k, t}-q_{i, \text { Belgium }, t}\right)$. The main parameter of interest is $\beta$ that denotes the speed of convergence. Under the null of no convergence, $\beta$ is equal to zero. In this case, a shock to $p_{i, k, t}$ is permanent. Convergence implies a negative $\beta$, with the approximate half-life of a shock to $p_{i, k, t}$ given by $-\ln (2) / \ln (1+\beta) .{ }^{11} \mathrm{Cecchetti}$ et al. (2002) also consider an alternative specification (based on work by Im et al., 2003), in which the coefficient $\beta$ is allowed to vary across countries $\left(\beta\right.$ is replaced by $\beta_{k}$ in this

\footnotetext{
${ }^{10}$ In this case, we include time effects on the right hand side of the convergence equations. Convergence in this case is understood as convergence to an average across the countries in our sample.

11 This formula is only exact for a simple AR(1) process. For more complicated processes, the half-lives can be computed, for each separate product, from the impulse response functions. The results are similar to the results we report from the simple formula. In general, the half-lives we obtained with these alternative computations were always between 1 and 2 years. We have also estimated Eq. (2) without including any lags, in which case the above formula for the half-life is exact (at the cost of ignoring potential serial correlation). Our estimated half-life in this case is only slightly higher (1.66 instead of 1.35 years).
} 
case); convergence here implies a negative $\beta$ for some countries $\left(\beta_{k}<0\right.$, for some $k$ ), as opposed to all countries as in Levin and Lin. We chose the Levin and Lin approach as it is the more conservative one-it is unlikely that the behavior of only one or two countries will lead us to reject the unit root hypothesis in this case. We do consider country-specific $\beta$ 's however, later in Section 3.3 in which we estimate a separate convergence equation for each country pair in our sample.

The dummies $\alpha_{i, k}$ capture product/country fixed effects that account for non-time dependent, product specific price differences across countries. Such effects could be transportation costs (measured as percentages of price differences), unobserved quality differences that vary by destination, or markup differences. The presence of the product/ country fixed effects in the estimation indicates that we are testing the relative version of the LOOP. In addition to the speed of convergence $\beta$, we are also interested in examining the absolute values of the $\alpha_{i, k}$ 's; large values of these product/country specific effects would indicate market segmentation, even if the relative version of the LOOP held in the data. The lags $\Delta p_{i, k, t-l}$ are used to account for possible serial correlation in the error term. ${ }^{12}$ As a robustness test on our results, we also estimated unpooled regressions by product, and the results were similar. We therefore only report results from the pooled regressions here.

Table 2, column 1, reports the estimation results for equation (base). The coefficient estimate for $\beta$ is -0.41 , with a $t$-statistic of $-24 \%$. Note that, in the pooled estimation, we have 30 years of data, and approximately 240 product and country specific dummies. The critical values reported in Levin and Lin (1992) for $t=25$ and $N=250$ (approximately our panel size) are $-21.98,-21.43$, and -21.13 at the $1 \%, 5 \%$, and $10 \%$, respectively. Based on these critical values, we can reject the null of a unit root (or no convergence). This result contrasts with the findings of Parsley and Wei (1996) or Frankel and Rose (1996) who find it hard to reject the unit root hypothesis when fixed effects are allowed in the panel framework. It is also remarkable that the implied half-life of a shock is according to our estimates 1.3 years. This is a much shorter interval than what is traditionally estimated with international data (5-6 years); interestingly enough, it corresponds roughly to Parsley and Wei's estimate for tradeable goods in the United States, a market that we would normally consider more integrated than Europe. ${ }^{13}$ Note, however, that Parsley and Wei's basic specification does not include destination specific fixed effects, while ours does. As mentioned above, such fixed effects may themselves be indicative of market segmentation. We therefore turn our attention to our estimates of the fixed effects next.

The product/country specific dummies are jointly significant at the $5 \%$ level. Rather than reporting the individual product/country fixed effects, Table 2 displays the country average fixed effects (i.e. the averages of the $\alpha_{i, k}$ across products by country), and the corresponding standard errors. By dividing these fixed effects by $-\beta$, we obtain the longterm, systematic price differentials across countries. The long-term price differentials take values between 5\% (France) and 17\% (U.K.) and are all highly significant. They indicate

12 The number of lags is determined using Campbell and Perron's (1991) top-down approach. We start by setting $L=5$, if the absolute value of the $t$-statistic for $\hat{\gamma}_{5}$ is less than 1.96 then we reset $L=4$ and reestimate the equation. We repeat this procedure until the $t$-statistic of the coefficient with the longest lag is greater than 1.96 .

13 For services, Parsley and Wei find lower convergence rates, with a median of about 4 years. 
Table 2

Results for specification with product/country fixed effects

\begin{tabular}{|c|c|c|c|c|c|c|}
\hline \multirow{2}{*}{$\begin{array}{l}\text { Dependent } \\
\text { variable: } \Delta p_{i, k, t} \\
p_{i, k, t-1}\end{array}$} & \multicolumn{2}{|l|}{ Base: BE } & \multicolumn{2}{|l|}{ Base: GE } & \multicolumn{2}{|l|}{ No base } \\
\hline & $\begin{array}{l}-0.41 \\
(0.017)\end{array}$ & $\begin{array}{l}-0.38 \\
(0.016)\end{array}$ & $\begin{array}{l}-0.48 \\
(0.019)\end{array}$ & $\begin{array}{l}-0.42 \\
(0.018)\end{array}$ & $\begin{array}{l}-0.37 \\
(0.015)\end{array}$ & $\begin{array}{l}0.32 \\
(0.014)\end{array}$ \\
\hline$\Delta e_{k, t}$ & - & $\begin{array}{l}-0.76 \\
(0.02)\end{array}$ & - & $\begin{array}{l}-0.66 \\
(0.02)\end{array}$ & - & $\begin{array}{l}-0.77 \\
(0.03)\end{array}$ \\
\hline$\Delta e_{k, t-1}$ & - & $\begin{array}{l}-0.14 \\
(0.03)\end{array}$ & - & $\begin{array}{l}-0.08 \\
(0.03)\end{array}$ & - & $\begin{array}{l}-0.08 \\
(0.03)\end{array}$ \\
\hline$\Delta e_{k, t-2}$ & - & $\begin{array}{l}0.05 \\
(0.03)\end{array}$ & - & $\begin{array}{l}0.09 \\
(0.03)\end{array}$ & - & $\begin{array}{l}0.08 \\
(0.03)\end{array}$ \\
\hline$\Delta e_{k, t-3}$ & - & $\begin{array}{l}0.03 \\
(0.03)\end{array}$ & - & $\begin{array}{l}0.08 \\
(0.03)\end{array}$ & - & $\begin{array}{l}0.05 \\
(0.03)\end{array}$ \\
\hline $\mathrm{Be}$ & - & - & $\begin{array}{l}-0.05 \\
(0.005)\end{array}$ & $\begin{array}{l}-0.04 \\
(0.004)\end{array}$ & - & - \\
\hline Fr & $\begin{array}{l}0.02 \\
(0.004)\end{array}$ & $\begin{array}{l}0.03 \\
(0.004)\end{array}$ & $\begin{array}{l}-0.02 \\
(0.004)\end{array}$ & $\begin{array}{l}-0.00 \\
(0.004)\end{array}$ & $\begin{array}{l}0.02 \\
(0.005)\end{array}$ & $\begin{array}{l}0.03 \\
(0.004)\end{array}$ \\
\hline $\mathrm{Ge}$ & $\begin{array}{l}0.04 \\
(0.005)\end{array}$ & $\begin{array}{l}0.03 \\
(0.004)\end{array}$ & - & $\begin{array}{c}- \\
(0.005)\end{array}$ & $\begin{array}{l}0.04 \\
(0.004)\end{array}$ & 0.03 \\
\hline It & $\begin{array}{l}0.04 \\
(0.005)\end{array}$ & $\begin{array}{l}0.07 \\
(0.004)\end{array}$ & $\begin{array}{l}0.00 \\
(0.004)\end{array}$ & $\begin{array}{l}0.02 \\
(0.004)\end{array}$ & $\begin{array}{l}0.04 \\
(0.005)\end{array}$ & $\begin{array}{l}0.07 \\
(0.005)\end{array}$ \\
\hline UK & $\begin{array}{l}0.07 \\
(0.005)\end{array}$ & $\begin{array}{l}0.08 \\
(0.005)\end{array}$ & $\begin{array}{l}0.04 \\
(0.004)\end{array}$ & $\begin{array}{l}0.04 \\
(0.004)\end{array}$ & $\begin{array}{l}0.07 \\
(0.005)\end{array}$ & $\begin{array}{l}0.08 \\
(0.005)\end{array}$ \\
\hline Lags of $\Delta p_{i, k, t}$ & yes (3) & yes (3) & yes (3) & yes (3) & yes (3) & yes (3) \\
\hline Prod.-count. dummies & yes & yes & yes & yes & yes & yes \\
\hline Time dummies & no & no & no & no & yes & yes \\
\hline
\end{tabular}

the presence of persistent price differences relative to Belgium - the U.K. estimate, for example, implies that during our sample period, U.K. quality adjusted prices are approximately $17 \%$ higher than in Belgium. Price differences of this magnitude seem at odds with the common wisdom view of market integration - despite the fact that the unit root hypothesis is rejected in the data. Comparing our results with the analogous findings of Parsley and Wei for the U.S., it seems that the big difference between Europe and the U.S. lies in the fixed effects. While our estimates of the speed of convergence are very similar, the fixed effects are high and statistically significant in Europe, which is probably not the case in the U.S.

The histogram of Fig. 4 provides a more detailed description of the product/country fixed effects. Here, the product/country dummies are averaged by market segment. Each bar in the histogram represents the percent price difference of the corresponding market segment in the country of interest relative to Belgium. Note that the pattern of price differences seems relatively robust to different market segments. The only exception is the luxury market segment in Germany, which represents the only product group with prices lower than in Belgium.

Columns 4 and 6 of Table 2 also report results based on regressions in which (a) Germany is used as the base country and (b) there is no numeraire country, but the comparison of price differences is relative to a cross-country average (the specification includes time effects in this case). The basic message of columns 4 and 6 is that our 




Fig. 4. Long-term average price differential by segment, relative to Belgium.

conclusions are not sensitive to the choice of the base country; the estimates of the convergence speed are very similar in both cases to the ones obtained with Belgium as the base country.

\subsection{The role of exchange rate changes}

The literature on the relative version of PPP has suggested that nominal exchange rate volatility in conjunction with short-term price rigidities may be important in explaining international price differences. To investigate the role of exchange rate changes, we also estimated the following equation:

$$
\Delta p_{i, k, t}=\alpha_{i, k}+\beta p_{i, k, t-1}+\sum_{l=1}^{L} \gamma_{l} \Delta p_{i, k, t-l}+\sum_{m=0}^{M} \delta_{m} \Delta e_{k, t-m}+\varepsilon_{i, k, t}
$$

The variable $e_{k, t}$ denotes the log of the exchange rate of country $k$ 's currency relative to the Belgian Franc. The lag structure of exchange rate changes is included to capture changes in cross-country price differentials that may result from short-term nominal rigidities. ${ }^{14}$ Fig. 3, plotting the exchange rates of the four countries in our sample

14 We should note that, once we include covariates in the basic convergence equation specified in the previous subsection, we can no longer employ the tables provided by Levin and Lin to test for the unit root hypothesis, as the distribution of the relevant statistics is not known under the null of a unit root. It is the results of Section 3.1 (without covariates) that allow us to reject the unit root hypothesis. The reason we include covariates (such as exchange rates) at this stage is to examine the robustness of the estimated speed of convergence to covariates, once we have established stationarity of prices in Section 2. 
relative to Belgium, suggests that this may be an important issue. For example, the decline in the price differential between the U.K. and Belgium in the period 1990-1992 coincides with the depreciation of the pound. Without controlling for this depreciation, we might be attributing this apparent "price convergence" to institutional changes aimed at fostering integration, when the true source of the change might in fact be just fortuitous movement of exchange rates in the right direction. And vice versa, there might be periods where, despite efforts to increase integration, we may observe a widening of price differentials because of short term nominal rigidities - that is, exchange rate changes that are not passed though onto local currency prices in the short run.

The results for the specification that includes exchange rate changes are displayed in Table 2, column 3. In the reported specification, we included the exchange rate change and its first three lags to capture pass-through effects that may spread over several years. All variables appearing in Eq. (3) are stationary-prices by virtue of the results in Section 3.1, while for exchange rate changes we established stationarity separately. There are two things to note in specification 3. First, our estimate of the speed of convergence hardly changes compared to the specification without exchange rates; the point estimate is -0.38 ( $t$-statistic: -23.3 ) implying a half-life of a shock of approximately 1.5 years. Nevertheless, the exchange rate change and its first two lags are highly significant. As expected, all coefficients are negative, and declining in absolute value as the lags get longer. The magnitude of $\Delta e_{k, t}$ is striking (point estimate: -0.76 , with a $t$-statistic of -32 ). It implies that only $24 \%$ of an exchange rate change gets passed through (on average) onto local prices in the short run. This is consistent with previous work on exchange rate pass-through that has documented local currency price inertia. Note, however, that the coefficient on the first lag is substantially smaller in absolute value (0.14). The robustness of the estimated speed of convergence to the inclusion of exchange rate changes suggests that, while exchange rate changes and nominal rigidities are important in the short run in explaining cross-country price differentials, our finding of fast relative price convergence is not due just to movements of exchange rates.

Of course, a natural objection to the above statement is that two of the countries in our sample (France and Germany) had quasi-fixed exchange rates relative to Belgium for most of our sample period. To investigate whether these quasi-fixed exchange rates may have had an impact on our results, we next turn to bilateral regressions examining the price differentials in each of the countries in our sample relative to Belgium.

\subsection{Country pairs}

Table 3 reports the convergence coefficients (standard errors in parentheses) obtained by estimating convergence equations for each country pair separately. The first row of numbers was obtained using Belgium as the base country, the second row using France, and so on. The striking feature of this table is that the estimated speeds of convergence are very high for virtually all countries in our sample. While there is some variation in the point estimates of $\beta$ (it ranges from -0.35 for the Italy/Belgium pair to -0.60 for Germany/France), the coefficient is always statistically significant and 
Table 3

Results for country pairs ${ }^{\mathrm{a}}$

\begin{tabular}{lllll}
\hline & FR & GE & IT & UK \\
\hline BE & -0.45 & -0.56 & -0.35 & -0.46 \\
& $(0.025)$ & $(0.056)$ & $(0.033)$ & $(0.077)$ \\
FR & & -0.60 & -0.50 & -0.58 \\
& & $(0.028)$ & $(0.019)$ & $(0.065)$ \\
GE & & -0.42 & -0.53 \\
& & & $(0.001)$ & $(0.0039)$ \\
IT & & & -0.38 \\
& & & $(0.0034)$ \\
\hline
\end{tabular}

${ }^{a}$ The estimated specifications include product fixed effects. The table reports the estimated $\beta$ coefficients from bilateral regressions, with standard errors in parentheses. For example, the coefficient -0.45 in the upperleft corner corresponds to a regression in which the dependent variable is the first difference of the BelgiumFrance price differential; the second number in the first row corresponds to the Belgium-Germany regression, etc. The reported specifications did not include exchange rate change lags. The results with exchange rate changes were very similar.

implies relatively short half-lives of price shocks (from 0.75 to 1.6 years). ${ }^{15}$ Note that, by estimating bilateral regressions, we give up the country dimension in our panel data set-we only exploit the time variation in price differences. In light of this, our results are remarkable. Most previous work on price convergence failed to reject the null of a unit root in the price series when time series data were used. The recent findings on relative price convergence are often attributed to the use of panel data sets, which allow the econometrician to exploit the cross-sectional dimension. This explanation, however, does not seem to apply to our case. Of course, we do exploit a richer than usual data set, in the sense that we have detailed data on multiple models.

The results in Table 3 were obtained using a specification that did not include exchange rate changes. Including exchange rate changes leaves the $\beta$ coefficients virtually unchanged; as before, the coefficients on the exchange rate changes are highly significant. A notable pattern concerning the exchange rate coefficients is that these are substantially higher in absolute value in regressions in which the U.K. is compared to another base country. For example, in the U.K./Belgium regression, the coefficient on $\Delta e_{k, t}$, where $e$ here denotes the exchange rate between the Belgian Franc and the British Pound, is 0.81 (standard error: 0.04), while the exchange rate coefficients for the other countries range between -0.42 and -0.69 . This suggests that nominal exchange rate volatility is more important in explaining price differences in the U.K., relative to the other countries in our sample. This is not surprising given that two out of the three remaining countries in our sample had a system of quasifixed exchange rates.

\footnotetext{
15 Note that the relevant critical values for this specification are the ones corresponding to $t=25$ and $N=50$, where $N$ here denotes the number of products. These critical values are $-10.89,-10.35$, and -10.06 at the $1 \%$, $5 \%$, and 10\% significance levels, respectively (Levin and Lin, 1992, Table 5). All the $t$-statistics of the estimated $\beta$ 's in Table 3 are less than -11 .
} 


\subsection{Progress towards integration?}

The previous results established (i) the persistence of long-term price differentials across countries and (ii) a relatively fast convergence to the long-run equilibrium after price shocks (half-lives of approximately 1.5 years). Our next question concerns the role of the integration process. Our panel data set, that spans a period of 30 years, is ideal for addressing this question. As discussed earlier, the European Commission has taken several measures over the past three decades to improve European integration. Ideally, we would like to relate potential declines in price dispersion directly to specific measures aimed at fostering integration. However, most of these measures were implemented gradually. The harmonization of "essential requirements" for example, was initiated as early as 1970, but did not become mandatory until 1993. Similarly, the " $12 \%$-rule" has existed since the late 1980's, but the European Commission did not demonstrate its intention to seriously enforce it until the late 1990s. Other measures, such as tax harmonization and transition to a system of quasi-fixed exchange rates, were also gradually implemented, while the transition to the EMU did not occur until late in our sample. Given this gradual enforcement of integration measures, we found it best to address the progress towards integration in the following two ways: first, we estimate convergence equations for different subperiods in our sample, and examine whether the long-term average price differentials are lower, and the speed of convergence higher, in the later subsamples; second, we interact the fixed effects and the speed of convergence in the regressions described in the previous subsections with trend variables. Each approach has its strengths and weaknesses that we discuss below.

Our primary hypothesis is that successful integration should translate to lower absolute price differentials. To the extent that the differentials reflected differences in observed costs (such as tax rates, different national requirements) or trade policies (VERs), the harmonization measures of the European Commission should have directly reduced them by eliminating these sources of price dispersion; to the extent that they reflected price discrimination (as in Italy), the removal of several barriers to arbitrage, the stricter enforcement of the $12 \%$ rule, and the increased transparency should similarly have contributed to their decline. The impact of the European Commission's activity is more ambiguous in cases where price differences have been driven by unobserved costs (as in the U.K., for example). To the extent that the higher costs of products sold in the U.K. arise from product specifications that are genuinely demanded by consumers, one would expect the price differentials to persist, as they reflect true product differentiation. But if these specifications were used as a pretense in order to keep markets segmented, crosscountry arbitrage should gradually lead to the erosion of higher prices, as consumers would be able to purchase the specifications of their choice. Furthermore, one would expect market integration (in the broader sense of the word) to lead to a general harmonization of costs; high cost distributors or dealers would have to lower their expenses in order to remain competitive.

A second question is whether the speed of convergence has changed over time. All else being equal, one would expect integration to speed up price convergence: shocks to prices should be eliminated faster if consumers or intermediaries can more easily engage in arbitrage. However, this expected increase in the speed of convergence may not occur if 
the absolute price differentials have declined as a result of integration. This is because of the commonly observed non-linearities in the speed of price convergence: large shocks and large price differences tend to be eliminated faster than small differences. If integration reduces price differences across countries, then price shocks may be eliminated more slowly, not because impediments to arbitrage have not diminished, but because the price differences to be eliminated are smaller compared to the pre-integration period.

To investigate the effect of integration on price dispersion we start by spliting our sample into two subperiods: 1970-1989 and 1990-2000. The reason for choosing this particular partition is that the year 1990 marks the beginning of an intense integration effort by the European Commission towards the end of "Europe 1992". We also experimented with other partitions (choosing for example the years 1985 or 1986 as the thresholds) and obtained qualitatively similar results. Although the splitting of the sample inevitably involves some degree of arbitrariness, it offers the advantage that we can employ the framework provided by Levin and Lin to derive the relevant test statistics.

The results from this exercise are summarized in Table 4. Columns 2 and 3 refer to a specification without exchange rate changes, while the last two columns include the first difference of the exchange rate and its lags to account for short-term nominal rigidities. The table reports the estimated long-term price differentials corresponding to the two subsamples, and the corresponding changes in these long-term price differentials. In both specifications there is a marked and statistically significant decline of absolute price differences, which is most pronounced in the case of Italy: the long-term price differentials decline there by approximately $14 \%$ between the two subperiods (in both specifications). The same pattern is evident in the other countries, though the declines there are lower. The inclusion of exchange rate changes does not affect the estimates of the absolute price declines in a significant way; this is consistent with the interpretation that the declines of

Table 4

The effects of the integration process results based on subperiods (base country: Belgium)

\begin{tabular}{|c|c|c|c|c|c|c|}
\hline \multirow[t]{2}{*}{ Dependent variable: $\Delta p_{i, k, t}$} & \multicolumn{3}{|c|}{ Without exr. changes } & \multicolumn{3}{|c|}{ With exr. changes } \\
\hline & $1970-1989$ & $1990-2000$ & Change & $1970-1989$ & $1990-2000$ & Change \\
\hline$p_{i, k, t-1}$ & $\begin{array}{l}-0.39 \\
(0.022)\end{array}$ & $\begin{array}{l}-0.75 \\
(0.035)\end{array}$ & $\begin{array}{l}-0.36 \\
(0.041)\end{array}$ & $\begin{array}{l}-0.60 \\
(0.024)\end{array}$ & $\begin{array}{l}-0.42 \\
(0.031)\end{array}$ & $\begin{array}{l}0.18 \\
(0.040)\end{array}$ \\
\hline $\mathrm{Fr}^{\mathrm{a}}$ & $\begin{array}{l}7.7 \\
(1.6)\end{array}$ & $\begin{array}{l}3.5 \\
(0.7)\end{array}$ & $\begin{array}{l}-4.2 \\
(1.7)\end{array}$ & $\begin{array}{l}11.5 \\
(0.9)\end{array}$ & $\begin{array}{l}2.4 \\
(1.0)\end{array}$ & $\begin{array}{l}-9.1 \\
(1.3)\end{array}$ \\
\hline $\mathrm{Ge}$ & $\begin{array}{l}11.9 \\
(1.5)\end{array}$ & $\begin{array}{l}7.7 \\
(0.7)\end{array}$ & $\begin{array}{l}-4.2 \\
(1.7)\end{array}$ & $\begin{array}{l}7.7 \\
(0.9)\end{array}$ & $\begin{array}{l}7.0 \\
(1.0)\end{array}$ & $\begin{array}{l}-0.7 \\
(1.3)\end{array}$ \\
\hline It & $\begin{array}{l}18.6 \\
(1.6)\end{array}$ & $\begin{array}{l}4.8 \\
(0.7)\end{array}$ & $\begin{array}{l}-13.8 \\
(1.7)\end{array}$ & $\begin{array}{l}27.7 \\
(1.0)\end{array}$ & $\begin{array}{l}13.8 \\
(1.2)\end{array}$ & $\begin{array}{l}-13.9 \\
(1.6)\end{array}$ \\
\hline UK & $\begin{array}{l}20.7 \\
(1.6)\end{array}$ & $\begin{array}{l}14.8 \\
(0.8)\end{array}$ & $\begin{array}{l}-5.9 \\
(1.7)\end{array}$ & $\begin{array}{l}25.2 \\
(0.9)\end{array}$ & $\begin{array}{l}19.0 \\
(1.1)\end{array}$ & $\begin{array}{l}-6.2 \\
(1.5)\end{array}$ \\
\hline Lags of $\Delta p_{i, k, t}$ & yes (3) & yes (3) & yes (3) & yes (3) & yes (3) & yes (3) \\
\hline Lags of $\Delta e_{i, k, t}$ & no & no & no & yes & yes & yes \\
\hline Prod.-count. dummies & yes & yes & yes & yes & yes & yes \\
\hline Time dummies & no & no & no & no & no & no \\
\hline
\end{tabular}

${ }^{a}$ The entries in the following cells represent the long-term price differentials, rather than the fixed effects; that is, the fixed effects have been divided by the estimated speed of convergence $-\beta$ and the standard errors have been adjusted appropriately. 
the absolute price differences reflect long-term structural changes rather than short-term exchange rate movements.

In contrast, the results regarding the speed of convergence are less clear-cut, and depend in an important way on the inclusion of exchange rates. Without exchange rate changes, the estimates imply an almost two-fold increase in the speed of convergence between the two subsamples. This result is however reversed once we account for exchange rate changes; the speed of convergence is now lower in the second subperiod, suggesting that if prices appear to be converging faster towards their long-term differentials in the second period, this is because of short-term movements of exchange rates in the right direction.

Our second approach for investigating the consequences of integration is to interact the fixed effects and/or speed of convergence with trend variables. We interpret these trend variables as applying only to our sample period: 1970-2000. The advantage of employing trend variables is that they allow for a continuous effect of integration on price dispersion, so that our conclusions are not the artifact of splitting the sample in arbitrary ways. The disadvantage is that, as with the inclusion of other covariates, the distribution of the relevant test statistics is no longer known under the null of the unit root. Despite this caveat, we employ the trend based estimation as a robustness check on our earlier results on subsamples; we should also note that the unit root hypothesis is rejected in our data based on both the results for the whole sample and the subsamples. To make sure that we are capturing the real effects of integration, rather than any nominal shocks, we include exchange rate changes in our specification, as we did previously in Eq. (3). Table 5 reports

Table 5

The effects of the integration process results based on interactions with trend variables (base country: Belgium)

\begin{tabular}{|c|c|c|}
\hline \multicolumn{3}{|l|}{ Dependent variable: $\Delta p_{i, k, t}$} \\
\hline$p_{i, k, t-1}$ & $\begin{array}{l}-0.45 \\
(0.015)\end{array}$ & $\begin{array}{l}-0.46 \\
(0.017)\end{array}$ \\
\hline$p_{i, k, t-1} *$ trend & - & $\begin{array}{l}0.002 \\
(0.001)\end{array}$ \\
\hline $\mathrm{Fr}$ & $\begin{array}{l}0.07 \\
(0.005)\end{array}$ & $\begin{array}{l}0.07 \\
(0.005)\end{array}$ \\
\hline Fr*trend & $\begin{array}{l}-0.003 \\
(0.0003)\end{array}$ & $\begin{array}{l}-0.003 \\
(0.0004)\end{array}$ \\
\hline $\mathrm{Ge}$ & $\begin{array}{l}0.01 \\
(0.005)\end{array}$ & $\begin{array}{l}0.01 \\
(0.005)\end{array}$ \\
\hline Ge*trend & $\begin{array}{l}0.001 \\
(0.0003)\end{array}$ & $\begin{array}{l}0.001 \\
(0.0004)\end{array}$ \\
\hline It & $\begin{array}{l}0.17 \\
(0.007)\end{array}$ & $\begin{array}{l}0.17 \\
(0.007)\end{array}$ \\
\hline It $*$ trend & $\begin{array}{l}-0.007 \\
(0.0004)\end{array}$ & $\begin{array}{l}-0.007 \\
(0.0004)\end{array}$ \\
\hline UK & $\begin{array}{l}0.13 \\
(0.006)\end{array}$ & $\begin{array}{l}0.13 \\
(0.006)\end{array}$ \\
\hline $\mathrm{UK} *$ trend & $\begin{array}{l}-0.003 \\
(0.0003)\end{array}$ & $\begin{array}{l}-0.003 \\
(0.0004)\end{array}$ \\
\hline Lags of $\Delta p_{i, k, t}$ & yes (3) & yes (3) \\
\hline Exchange rate change and lags & yes & yes \\
\hline Prod.-count. dummies & yes & yes \\
\hline
\end{tabular}


the results. Column 2 considers the effect of integration on the absolute price differentials. The underlying equation is:

$$
\Delta p_{i, k, t}=\alpha_{i, k}+\tilde{\alpha}_{k} * \text { trend }+\beta p_{i, k, t-1}+\sum_{l=1}^{L} \gamma_{l} \Delta p_{i, k, t-l}+\sum_{m=0}^{M} \delta_{m} \Delta e_{k, t-m}+\varepsilon_{i, k, t}
$$

We focus on a specification where only the country average fixed effects $\tilde{\alpha}_{k}$ are interacted with a trend, so that our trend coefficient captures the effect of integration on average price differentials in each market relative to Belgium. It is important to note here that we use the trend only to capture gradual integration during our sample period, and not long-run growth out of sample. The estimated coefficients indicate that the average price levels in France, the United Kingdom, and especially in Italy have declined significantly relative to Belgium. The annual declines range from $0.7 \%$ (France) to $1.5 \%$ (Italy). In contrast, the average price level in Germany has increased (moderately) relative to Belgium. Yet the country fixed effects show that Germany had a lower price level than France, Italy, and the United Kingdom at the beginning of the sample. The change of the fixed effect for Germany thus shows convergence of the German price level to the price levels in the other countries. Overall, these country averages indicate a gradual increase in integration.

Column 3 of Table 5 considers the effect of integration on the speed of convergence. The underlying equation here is:

$$
\begin{aligned}
\Delta p_{i, k, t}= & \alpha_{i, k}+\tilde{\alpha}_{k} * \text { trend }+\beta * p_{i, k, t-1}+\tilde{\beta} * \text { trend } * p_{i, k, t-1}+\sum_{l=1}^{L} \gamma_{l} \Delta p_{i, k, t-l} \\
& +\sum_{m=0}^{M} \delta_{m} \Delta e_{k, t-m}+\varepsilon_{i, k, t}
\end{aligned}
$$

The estimates again indicate that integration has had little effect on the speed of convergence; if anything, the speed of convergence has decreased (the decrease is significant at the $10 \%$ level). This may follow from the presence of non-linearities discussed above. If there is a "band of inaction", as suggested by Obstfeld and Taylor (1997), then arbitrage will only occur when deviations from the LOOP are sufficiently large, so that small price differences will be eliminated slower than big differences. Asplund and Friberg's (2001) recent findings on the speed of convergence in products sold in duty-free shops provide strong support for this argument.

In sum, independent of whether we use subsamples or trend variables, we conclude that integration has led to a gradual reduction in the average price differentials during 1970 2000 , yet the speed of convergence in response to shocks has remained more or less unaffected. This is perhaps not surprising given that our estimate of the speed of convergence is comparable to the speed of convergence in the more integrated U.S. market.

\subsection{Convergence to the absolute LOOP}

So far, our discussion has focused on convergence to the relative version of the LOOP. While the results of regressions with fixed effects indicate the presence of long-run price 
differentials across countries, our subsequent results on subsamples and trends suggest that these differentials are declining over time. Given this downward trend in the average cross-country differentials, it is interesting to examine how the stricter version of LOOP, the absolute version, fares during this period.

The basic equation we estimate to test for convergence to the absolute LOOP is:

$$
\Delta p_{i, k, t}=\beta p_{i, k, t-1}+\sum_{l=1}^{L} \gamma_{l} \Delta p_{i, k, t-l}+\varepsilon_{i, k, t}
$$

This equation is similar to Eq. (2), except for the absence of the product/country fixed effects. The omission of the fixed effects may seem odd given that such effects appear to be statistically significant in our previous regressions. However, given the evidence presented in Section 3.4 that these effects are declining over time, we wanted to test whether the unit root hypothesis can still be rejected when fixed effects are omitted from the specification. The hypothesis we are thus testing in this subsection is that the price differences are converging towards zero in the long run.

The results from this exercise are reported in Table 6, columns 2 and 4 . The hypothesis of a unit root is easily rejected. The coefficient $\beta$ is negative, with $t$ statistics lower than -10 , while the critical values according to Levin and Lin (1992) for $T=25, N=250$, and no intercepts, are -2.34 at the $1 \%$ level and -1.67 at the $5 \%$ level. Columns 3 and 5 of the same table report results from a specification that includes, in addition to the right-hand side variables in Eq. (6), the exchange rate change and its lags. The estimated speeds of convergence seem robust to the inclusion of exchange rate changes. The implied half-lives of a shock range from approximately 2.2 years (based on the estimate in column 4) to 8.3 years (based on column 3 ). These numbers seem more in line with the estimates traditionally obtained in the International literature on price convergence.

Table 6

Convergence to the absolute LOOP (base country: Belgium)

\begin{tabular}{|c|c|c|c|c|}
\hline \multicolumn{5}{|c|}{ Dependent variable: $\Delta p_{i, k, t}$} \\
\hline$p_{i, k, t-1}$ & $\begin{array}{l}-0.13 \\
(0.010)\end{array}$ & $\begin{array}{l}-0.08 \\
(0.009)\end{array}$ & $\begin{array}{l}-0.28 \\
(0.015)\end{array}$ & $\begin{array}{l}-0.21 \\
(0.013)\end{array}$ \\
\hline$\Delta e_{k, t}$ & - & $\begin{array}{l}-0.81 \\
(0.024)\end{array}$ & - & $\begin{array}{l}-0.78 \\
(0.024)\end{array}$ \\
\hline$\Delta e_{k, t-1}$ & - & $\begin{array}{l}0.05 \\
(0.029)\end{array}$ & - & $\begin{array}{l}-0.02 \\
(0.027)\end{array}$ \\
\hline$\Delta e_{k, t-2}$ & - & $\begin{array}{l}0.26 \\
(0.027)\end{array}$ & - & $\begin{array}{l}0.19 \\
(0.027)\end{array}$ \\
\hline$\Delta e_{k, t-3}$ & - & $\begin{array}{l}0.27 \\
(0.027)\end{array}$ & - & $\begin{array}{l}0.18 \\
(0.027)\end{array}$ \\
\hline Lags of $\Delta p_{i, k, t}$ & yes (3) & yes (3) & yes (3) & yes (3) \\
\hline Prod.-count. dummies & no & no & no & no \\
\hline Only country dummies & no & no & no & no \\
\hline Only product dummies & no & no & yes & yes \\
\hline
\end{tabular}


There are two obvious caveats to these results on absolute convergence. First, our analysis focuses on countries with more or less similar tax regimes. Other European countries (such as the Scandinavian and Ireland) have substantially higher VAT rates, so convergence to the absolute LOOP might be very hard to establish with respect to these countries. Second, specification (6) pools data across products. Including product (but not country) dummies reduces the estimated $\beta$ coefficients to values around -0.20 , but in this case there is no correspondence between our specification and the specifications considered in Levin and Lin. Accordingly, the appropriate critical values for testing the unit root hypothesis are not available to us. ${ }^{16}$ We therefore employed an alternative approach and estimated Eq. (6) on a product-by-product basis. There are too many coefficients to report in this case, but the general picture that emerges from the estimation supports our conclusions from the previous paragraph: the estimated convergence speed is low. The $\beta$ coefficients vary from -0.15 to -0.05 , implying half-lives between 4 and 13 years. While the majority of the coefficients are statistically significant, the number of the ones that are not is substantial.

Overall, our results on the absolute version of the LOOP indicate that, while the hypothesis of a unit root is rejected, the results are weaker compared to the tests for the relative version. The fact that the fixed effects estimated in previous equations were jointly significant, also argues in favor of the hypothesis that deviations from the absolute LOOP still exist-even if we cannot formally reject convergence when estimating Eq. (6). This is not surprising given that some impediments to arbitrage still exist in European markets. Nevertheless, our estimates based on subsamples and trends in the previous subsections in conjunction with the results on absolute convergence suggest that violations of the LOOP are diminishing over time, and are certainly not as pronounced as previously found in studies of international markets. Overall, we interpret the combined empirical results as suggesting that prices converge quickly to structurally determined cross-country differentials, while these differentials are themselves - as a result of integration efforts - slowly declining over time; accordingly, we cannot reject the hypothesis that the price differentials are converging towards zero in the long run.

\section{Conclusions}

This paper set out to investigate convergence to the LOOP in international markets using detailed product-level data from a period and a region that were characterized by a distinct effort to integrate national markets. We focused on a market that - thanks to its notorious cross-country price differences-has become the target of an intense integration campaign by the European Commission in the last decade. If there were

16 The results from specifications that include product specific, but not country specific dummies, are reported in columns 3 and 4 of Table 6 . Given that the critical values are not available to us, we cannot formally test the unit root hypothesis in these two cases. But we can get an idea in which direction the $\beta$ coefficients change when product dummies are included. 
one case where we would expect to see evidence of integration (or at least progress towards it), it would be in this setting.

Our results confirm this expectation. Our findings provide strong evidence in favor of the relative version of the LOOP that contrasts with earlier evidence on international price dispersion. Furthermore, we cannot reject the hypothesis of convergence to the absolute version of the LOOP, though the results regarding this version are generally weaker.

In particular, our results regarding the relative version of the LOOP imply half-lives of shocks of 1.3-1.6 years. These estimates are substantially shorter than the ones estimated in earlier work. At the same time, we found the country/product fixed effects capturing longterm, persistent price differentials across markets to be jointly significant, having magnitudes that seem hard to reconcile with the notion of integrated markets. We argued that the fixation with the relative version of the LOOP (which is usually dictated by data constraints) may lead to erroneous conclusions regarding integration, if market segmentation manifests itself in relatively stable cross-country price differentials; a thorough examination of the country fixed effects is accordingly equally important. Having said this, the evidence we present based on estimation of subsamples suggests that these effects are declining over time, making the distinction between national and international markets less pronounced. This is after all what economic integration in Europe was supposed to achieve.

We would like to conclude by reminding the reader that our results refer to a market that has undergone many changes in the last two decades in order to become more integrated. We are therefore hesitant to generalize our findings to other markets. Rather, we view them as evidence that the progress towards integration in Europe has had visible effects on cross-country price dispersion that are reflected in tests of the LOOP.

\section{Acknowledgements}

We gratefully acknowledge funding from a National Science Foundation Grant to the NBER (Grant SBR-9371979), an Alfred P. Sloan Foundation Research Fellowship to Goldberg, and a grant by the Belgian Science Foundation (Flanders), and by the University of Antwerp (B.O.F.) to Verboven. We also thank the editor, two anonymous referees, and participants at many seminars in the U.S. and Europe for helpful comments and suggestions.

\section{References}

Asplund, M., Friberg, R., 2001. The law of one price in Scandinavian duty-free stores. American Economic Review 91, 1072-1083 (September).

Bureau of European Consumers Unions (BEUC), 1981. Report on Car Prices in the EEC Countries, BEUC/71/ 81, 1981, Brussels.

Bureau of European Consumers Unions (BEUC), 1986. Car Prices in the EEC Countries, BEUC/121/86, 1986, Brussels.

Bureau of European Consumers Unions (BEUC), 1989. Car Price and Progress towards 1992, BEUC/10/89, 1989, Brussels.

Bureau of European Consumers Unions (BEUC), 1992. Parallel Imports for Cars in the EC, BEUC/222/92, 1992, Brussels. 
Campbell, J., Perron, P., 1991. Pitfalls and opportunities: what macroeconomists should know about unit roots. In: Blanchard, O., Fisher, S. (Eds.), NBER Macroeconomics Annual, vol. 6. MIT Press, Cambridge, MA.

Cecchetti, S., Nelson, M., Sonora, R., 2002. Price level convergence among United States cities: lessons for the European central bank. International Economic Review 43 (4), 1081-1099 (November).

Crucini, M., Telmer, C., Zachariadis, M., 2000. Dispersion in Real Exchange Rates Manuscript, May.

Degryse, H., Verboven, F., 2000. Car price differentials in the European union: An Economic Analysis, Report Prepared for the European Commission.

Engel, C., Rogers, J.H., 1996. How wide is the border? American Economic Review 86, $1112-1125$ (December).

Frankel, J.A., Rose, A., 1996. A panel project on puchasing power parity: mean reversion within and between countries. Journal of International Economics 40, 209-224.

Gagnon, J.E., Knetter, M., 1995. Markup adjustment and exchange rate fluctuations: evidence from panel data on automobile exports. Journal of International Money and Finance 14 (2), 289-310.

Goldberg, P., Knetter, M., 1997. Goods prices and exchange rates: what have we learned? Journal of Economic Literature 35, 1243-1272 (September).

Goldberg, P., Verboven, F., 2001. Market integration and convergence to the law of one price: evidence from the european car market, NBER Working Paper, 8402. July.

Goldberg, P., Verboven, F., 2001. The evolution of price dispersion in the European car market. Review of Economic Studies, 811-848 (October).

Haskel, J., Wolf, H., 2001. The law of one price-a case study. Scandinavian Journal Economics 103, 545-558.

Im, K., Pesaran, M.H., Shin, Y., 2003. Testing for unit roots in heterogeneous panels. Journal of Econometrics $115,53-74$.

Knetter, M., Slaughter, M., 2001. Measuring product-market integration. In: Goldberg, L. (Ed.), Topics in Empirical International Economics: A Festschrift in Honor of Robert E. Lipsey. NBER Conference Volume.

Krugman, P., 1987. Pricing to market when the exchange rate changes. In: Richardson, J.D., Arndt, S. (Eds.), Real-Financial Linkages among Open Economies. MIT Press, Cambridge, MA.

Levin, A. and C. Lin, 1992. Unit Root Tests in Panel Data: Asymptotic and Finite-Sample Properties, unpublished manuscript. University of California, San Diego. Discussion Paper 92-23, May 1992.

Obstfeld, M., Rogoff, K., 2000. The six major puzzles in international macroeconomics: is there a common cause? NBER Working Paper 7777. July.

Obstfeld, M., Taylor, A., 1997. Nonlinear aspects of goods-market arbitrage and adjustment: Heckscher's commodity points revisited. Journal of Japanese and International Economics 11 (2), 441-479 (December).

Papell, D.H., 1997. Searching for stationarity: purchasing power parity under the current float. Journal of International Economics 43, 313-332.

Parsley, D., Wei, S.J., 1996. Convergence to the law of one price without trade barriers or currency fluctuations. Quarterly Journal of Economics 111, 1211-1236 (November).

Parsley., D., Wei., S.J., 2001. Explaining the border effect: the role of exchange rate variability, shipping costs, and geography. Journal of International Economics 55 (1), 87-106 (October, 2001).

Rogers, J., 2002. Monetary Union, Price Level Convergence, and Inflation: how close is Europe to the United States? Manuscript, July.

Taylor, A., 2001. Potential pitfalls in the purchasing-power-parity puzzle? Sampling and specification biases in mean-reversion tests of the law of one price. Econometrica 69 (2), 473-498 (March).

Taylor, A., 2002. A century of purchasing power parity. Review of Economics and Statistics 84, 139-150.

Wei, S.J., Parsley, D., February 1995. Purchasing power dis-parity during the floating rate period: exchange rate volatility, trade barriers, and other culprits. NBER Working Paper 5032. 